\title{
Description of Missouri children who suffer burn injuries
}

\author{
K S Quayle, N A Wick, K A Gnauck, M Schootman, D M Jaffe
}

\begin{abstract}
Objective-This study uses Missouri's inpatient and outpatient $E$ code data system to describe the demographic characteristics of Missouri children who suffered burn injuries during 1994 and 1995.

Methods-Retrospective review of Missouri $E$ code data.

Results-Altogether 8404 children aged 0-14 years were treated for burn injuries in Missouri hospitals during 1994 and 1995. The rate of burn injury in Missouri children was 339 per 100 000/year. African-American boys 0-4 years living in urban counties were at increased risk. In addition, African-American girls ages 0-4 years living in counties with a high poverty rate had raised burn injury rates. Burns from hot objects and scalds from hot liquids caused more than half of the burns.

Conclusions-Hospital based E coding has proven an invaluable tool for the study of burns and will, no doubt, prove equally useful for other injuries.

(Injury Prevention 2000;6:255-258)
\end{abstract}

Keywords: burns; E codes

Fire and burns are the third leading cause of unintentional injury death in American children, ${ }^{1}$ as well as a significant cause of morbidity. ${ }^{2}$ Epidemiology can be used to identify populations at increased risk upon whom interventions to decrease the incidence of such injuries could be focussed. ${ }^{34}$ Previous studies primarily used hospital records of admitted patients, ${ }^{5-9}$ or provided regional burn data through review of records at selected hospitals. ${ }^{10}$ No statewide studies describing burn injured children treated as inpatients or outpatients have been reported. In 1993, Missouri and Connecticut became the first states to mandate the collection of outpatient as well as inpatient external cause of injury ( $E$ code) data ${ }^{11}$ Since then, seven other states have made similar mandates. This study uses the Missouri E code data system to describe children with burn injuries on a statewide basis.

Department of Emergency Medicine, Bowman Gray School of Medicine

N A Wick

Correspondence to: Dr Kimberly S Quayle, Division of Emergency Medicine, St Loui Children's Hospital, One Children's Place, St Louis, Missouri 63110-1077, USA (quayle@a1.kids.wustl.edu) records in the state contained an E code diag- the first year. Ninety two per cent of all injury nosis in 1994, and 95\% in 1995 (unpublished data, Missouri Center for Health Information, Management, and Epidemiology, Missouri Department of Health). A burn injury was defined as a hospital visit with a burn $\mathrm{N}$ code (nature of injury) or E code (external cause of injury) from the International Classification of Diseases, ninth revision, clinical modifications. ${ }^{12}$ Burn N codes are 940-949.99. Fire and burn E codes include E890-899 (fire and flame, unintentional); E958.1, E968.0, E988.1 (fire and flame, intentional or undetermined); E924.0-.9 (hot object or substance, unintentional); E958.2, E958.7, E961, E968.3, E988.2, E988.7 (hot object or substance, intentional or undetermined). Children were included if their first injury diagnosis listed in the state database was a burn, even if the $\mathrm{E}$ code was different than the specified fire and burn E codes listed above. For example, children injured by fireworks (E923.0) or electrical current (E925.0) were included if their $\mathrm{N}$ code designated a burn (940-949.99). The data were provided by the Missouri Department of Health to study investigators in aggregate form, without patient specific identifiers. The variables included patient age, sex, race, county of residence, E code, inpatient/ outpatient status, and month of injury.

Missouri county population density was classified using the United States Department of Agriculture's designation of counties as metropolitan or non-metropolitan. ${ }^{13}$ This classification system is based on a county's population density and proximity to large cities (>50 000 population).

The percentage of each county's population living below the poverty level was classified using the 1990 United States census data. ${ }^{14} \mathrm{~A}$ high poverty county was defined as one with $\geqslant 20 \%$ of the population living below the poverty level. Injury rates were calculated using the number of burns as the numerator and the population in 1994 and 1995 as the denominator. Taylor's method for calculating the confidence intervals of the relative risks was used to determine significant differences in the rates, using EPI-Info version 6. We used Poisson regression to model the observed injury rates using the variables of age, race, sex, county poverty level, and type of county (metropolitan $v$ non-metropolitan) Variables were added to the model based on the likelihood ratio test, which has a $\chi^{2}$ distribution, and important changes in the parameter estimates of the already included variables. We calculated model based injury rates from the parameter estimates of the variables included in the "best" regression model. A p value of 0.05 or less was considered statistically significant. ${ }^{15}$ 
Table 1 Burn injury rates in Missouri children, 1994-95

\begin{tabular}{ll}
\hline & $\begin{array}{l}\text { Burn injury rates } \\
\text { (per 100 000/year) }\end{array}$ \\
\hline Age (years) & \\
$0-14$ & 339 \\
$0-4$ & 660 \\
$5-14$ & 184 \\
Race & \\
$\quad$ African-American & 592 \\
White & 291 \\
Sex & \\
Boys & 392 \\
Girls & 283 \\
Locale & \\
Metropolitan counties & 363 \\
Non-metropolitan counties & 296 \\
High poverty counties & 490 \\
Low poverty counties & 247 \\
\hline
\end{tabular}

\section{Results}

In 1994 and 1995, 8404 children ages 0-14 years were treated for burn injuries in Missouri hospitals; $88 \%$ as outpatients. Ninety four per cent were Missouri residents. The youngest children accounted for the largest number of patients; $63 \%$ were children ages $0-4$ years, $18 \%$ were $5-9$ years, and $19 \%$ were $10-14$ years. Seventy one per cent were white, $24 \%$ were African-American, and 5\% were another race or unknown. Fifty nine per cent were boys. After excluding 494 out-of-state children, 7910 injuries remained for analysis.

The burn injury rate for all Missouri children ages 0-14 years was 339 per 100 000/ year (table 1). Children ages $0-4$ years had a higher rate (660 per $100000 /$ year) than children 5-14 years (184 per 100 000/year). African-American children had a rate of 592 per 100 000/year and white children 291 per 100 000/year. Boys had a rate of 392 per 100 000/year and girls 283 per 100000 year.

The leading causes of burn injuries were hot objects, accounting for $38 \%$ of the injuries, followed by scalds, $26 \%$ (fig 1 ). The causes of

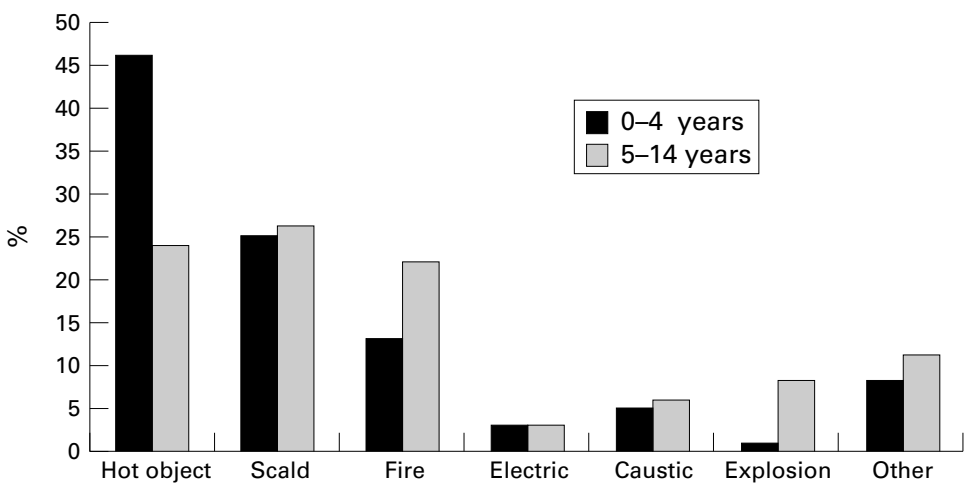

Figure 1 Causes of burn injury in Missouri children by age group.

Table 2 Model based rates of burn injuries among children ages 0-4 years, 1994-95. Rates per 100 000/year with 95\% confidence intervals shown in parentheses

\begin{tabular}{llllll}
\hline & Metropolitan & & \multicolumn{2}{l}{ Non-metropolitan } & \\
\cline { 2 - 3 } \cline { 5 - 5 } & African-American & White & & African-American & White \\
\hline Boys & & & & \\
$\begin{array}{c}\text { Poverty } \\
\text { High }\end{array}$ & $1290(1192$ to 1360$)$ & $877(803$ to 941$)$ & $820(728$ to 909$)$ & $773(715$ to 822$)$ \\
$\quad$ Low & $1126(1011$ to 1226$)$ & $680(647$ to 705$)$ & & $939(857$ to 1010$)$ & $600(565$ to 629$)$ \\
Girls & & & & \\
$\begin{array}{c}\text { Poverty } \\
\text { High }\end{array}$ & $1357(1234$ to 1452$)$ & $599(548$ to 647$)$ & & $1196(1076$ to 1299$)$ & $528(488$ to 566$)$ \\
Low & $809(740$ to 869$)$ & $465(441$ to 486$)$ & $713(644$ to 777$)$ & $410(385$ to 433$)$ \\
\hline
\end{tabular}

Key points

- The rate of burn injury in Missouri children 0-14 years was 339 per 100 000/ year.

- Young African-American boys living in urban counties and young AfricanAmerican girls living in high poverty counties were at increased risk for burn injury.

- State E code data systems can be important tools for the study of burns and other injuries.

burn injuries differed markedly between the younger and older children. Older children were more often injured by fires and explosions and younger children by hot objects. Intentional injuries (child abuse or assault) were reported to account for 62 burns $(0.7 \%)$. Almost one third of all injuries took place in June, July, or August. There was a significantly higher number of burns in July than other months, $13 \%$ of the total $(\mathrm{p}<0.001)$. Explosions caused $18 \%$ of the burns during July; in contrast, explosions accounted for only $4 \%$ of the total during the entire two year period. Sixty one per cent of all burns caused by explosions occurred during July.

There are 115 counties in Missouri, including St Louis City, an equivalent geopolitical unit. There are 93 non-metropolitan Missouri counties, and 22 metropolitan counties. Sixty nine per cent of Missouri children live in metropolitan counties and $31 \%$ live in nonmetropolitan counties. There are 39 high poverty Missouri counties and 76 low poverty counties. Seventeen per cent of Missouri children live in high poverty counties, while $83 \%$ live in low poverty counties. All high poverty counties, with the exception of St Louis City, were also classified as non-metropolitan.

Children in metropolitan counties had a slightly higher injury rate (363 per 100 000/ year) than those in non-metropolitan counties (296 per 100 000/year) (table 1). Those in high poverty counties also had higher rates relative to low poverty counties, 490 and 247 per 100 000/year, respectively.

Using Poisson regression, the variables of age, sex, race, poverty level, and type of county were included in the model to determine adjusted burn injury rates (table 2). In addition, injury rates for African-American compared with white children depended on the sex of the child and the poverty level of the county where the child lived. Using this model, we calculated injury rates using the variables listed. The highest rates were found among children $0-4$ years of age. In particular, the injury rates for African-American boys who resided in metropolitan counties were raised, for both high poverty (1290 per 100 000/year) and low poverty counties (1126 per 100 000/ year). Furthermore, among children in this age group, burn rates for African-American girls in high poverty counties were high in both metropolitan and non-metropolitan counties, 1357 and 1196 per 100 000/year, respectively. Injury 
rates were also raised among African-American boys $0-4$ years of age regardless of poverty or type of county, ranging from 600 to 880 per 100 000/year. Injury rates for white children and older children 5-14 years of age were generally much lower.

\section{Discussion}

This study of Missouri children demonstrates how a statewide, population based $\mathrm{E}$ code database can be used to describe burn injuries in children and identify populations at increased risk. In general, children ages $0-4$ years had a higher burn injury rate than older children-a finding similar to other US reports. ${ }^{5-10}$ Investigators in Massachusetts found an estimated incidence rate for $0-2$ year olds of 72 per 10000 patient years. ${ }^{10}$ We found that African-American boys ages $0-4$ years in urban counties and African-American girls in high poverty counties had raised injury rates. Like our study, MacKay and colleagues found that patients living in high poverty areas had higher rates of burns. ${ }^{10} \mathrm{~A}$ report from Baltimore also found that the majority of their hospitalized burn patients came from lower socioeconomic status homes. ${ }^{8}$

Scalds and fire related burns were the most common causes of burn injury in studies of hospitalized children, ${ }^{5-7} 9$ while hot objects and scalds were the most prominent causes of burns in our population who were predominantly outpatients. A study of children seeking care for burns in an urban emergency department also found contact burns as the leading cause of injury. ${ }^{16}$ Contact with hot objects is less likely to cause serious burns requiring hospital admission than those caused by scalds or flames, which often involve larger burn surface areas. Studies from other countries also found a predominance of young children hospitalized for burns, with scalds as the most common mechanism of injury. ${ }^{17-23}$ Outpatient studies in children reported from other countries describe similar causes as ours. ${ }^{24-28}$

This study demonstrated a 1:4 ratio of children hospitalized for burns compared with children treated as outpatients. The number of burn deaths, hospital admissions, and incidence follow a pyramidal distribution, similar to a recent report, which described 5500 burn deaths, 51000 burn hospital admissions, and 1.25 million burn incidents occurring each year in the US. ${ }^{29}$

Our study showed a higher rate of burn injury in the summer months, in contrast to other reports that found higher rates in winter months or no seasonal variation. ${ }^{18} 2728$ The increased number of injuries caused by explosions in July (the month with the highest numbers of burns) suggest that fireworks associated with the Independence Day holiday may be a factor. Another report describes injuries due to fireworks clustered around this holiday, with burns being the most common type of injury. ${ }^{30}$

Although the use of statewide outpatient E code data allows for a description of injuries that would have been otherwise difficult to obtain, these data have some limitations.
Because of confidentiality concerns by the state, our data were only available in aggregate form, presenting several difficulties. The geographic level was the patient's county of residence, instead of patient postal code or census tract. This limited our ability to perform a more detailed analysis, which may have identified other geographic and socioeconomic risk factors. In addition, we were not able to review patient records or categorize severity. We were also unable to track duplicated injuries which may have occurred if patients were seen in follow up visits for the same injuries, or if patients were transferred to another hospital for care. This would overestimate the number of the injured children, and thereby the injury rate, although we expect the magnitude of the overestimation to be small.

On the other hand, the total number of reported burn injuries underestimates the true incidence, as the data describe only inpatient and outpatient visits to hospitals. Patients who do not seek medical care for their injuries, or patients who visit their physicians are not captured in this database. A previous study reported that large proportions of children are treated for injuries, including burns, in clinics rather than emergency departments. ${ }^{31}$ This effect may result in under-reporting of burn injuries, especially minor burns, and those occurring in rural counties without nearby hospitals. As a result, our findings only apply to burns treated at emergency departments and those that required hospitalization.

Surveillance of injuries is an integral part of injury control and prevention programs. Vital statistics, hospital based trauma registries, national surveys, and E coded hospital discharge datasets have been used to describe the incidence of injuries. ${ }^{32-38}$ The inclusion of outpatient data has been identified as a priority for local and national injury surveillance. ${ }^{39} 40$ In 1999, the American Academy of Pediatrics Committee on Injury and Poison Prevention recommended the mandate of $\mathrm{E}$ codes in state hospital discharge data systems to establish priorities for child and adolescent injury prevention programs. ${ }^{41}$ Currently, 23 states mandate $\mathrm{E}$ coding in their hospital discharge data systems and nine states mandate $\mathrm{E}$ coding in their hospital emergency department data systems. ${ }^{11}$ As more states mandate reporting and collection of outpatient and inpatient $\mathrm{E}$ code data, large databases will be created to provide valuable information for policymakers and clinicians with interests in injury prevention. Accurate, specific, and standardized reporting of the $\mathrm{E}$ code data will need to be incorporated as well. ${ }^{42-44}$

\section{Implications for prevention}

This study demonstrates the value of statewide inpatient and outpatient $\mathrm{E}$ code databases. Compared with previous reports, this description of children with burn injuries represents a more complete summary as it includes data from all hospitals in Missouri, and includes emergency department visits as well as hospital inpatients. Important conclusions can be de- 
rived from these data, with respect to who is being injured, where they live, and how the injuries occur. This information should allow for the design of injury prevention programs and targeting high risk populations. In the case of burn injuries in Missouri children, prevention strategies might be directed toward African-American boys ages $0-4$ years residing in metropolitan counties, as well as AfricanAmerican girls in counties where at least $20 \%$ of the families live in poverty. Prevention efforts might concentrate on ways to reduce injuries as a result of contact and scald burns through surveillance of hot objects and liquids in children's environments. Just as importantly, the data could also be used to track the effect of such interventions on a large scale.

The authors greatly appreciate the collaboration with Cherie Crowe (former Chief, Office of Injury Control, Division of Health Resources, Missouri Department of Health) and Garland Land (Director, Division of Health Resources, Missouri Department of Health)

1 Baker SP, Fingerhut LA. Injury to children and teenagers: state by state mortality facts. Baltimore, MD: Johns Hopkins Center for Research and Policy, 1996.

2 Gallagher SS, Finison K, Guyer B, et al. The incidence of injuries among 87000 Massachusetts children and adolescents: results of the 1980-81 Statewide Childhood adolescents: results of the $1980-81$ Statewide Childhood Injury Prevention Program Sur

3 McLoughlin E. A simple guide to burn epidemiology. Burns 1995;21:217-20.

4 McLoughlin E. A simple guide to burn prevention. Burns 1995;21:226-9.

5 Simon PA, Baron RC. Age as a risk factor for burn injury requiring hospitalization during early childhood. Arch Pediatr Adolesc Med 1994;148:394-7.

6 Palumbo L, Budin WC. A descriptive summary of New Jersey's 1985 burn population. F Burn Care Rehabil 1990;11 565-72.

7 Rossignol AM, Locke JA, Burke JF. Paediatric burn injuries in New England, USA. Burns 1990;16:41-8.

8 Libber SM, Stayton DJ. Childhood burns reconsidered: the child, the family, and the burn injury. $f$ Trauma 1984;24: 245-52.

9 Morrow SE, Smith DL, Cairns BA, et al. Etiology and outcome of pediatric burns. I Pediatr Surg 1996;31:329-33.

10 MacKay A, Halpern J, McLoughlin E, et al. A comparison of age specific burn injury rates in five Massachusetts age specific burn injury rates in five Massach

11 American Public Health Association, Data Committee of the Injury Control and Emergency Health Services Section. How states are collecting and using cause of injury data. San Francisco, CA: American Public Health Association, 1998.

12 US Department of Health and Human Services. International Classification of Diseases. 9th revision. Clinical modifications. 6th Ed. Washington, DC: US Department of Health and Human Services. Public Health Service, Health Care Financing Administration, DHHS Publication No (PHS) 97-120, 1997.

13 Anonymous. Economic research service's 1989 revised county topology for Missouri. Washington, DC. United States Department of Agriculture, Division of Economic ReDepart search Service, 1997. http://www.econ ag gov/epubs/other typolog/typ 89 mo.txt.

14 Anonymous. Missouri poverty levels. St Louis: Office of Social and Economic Data Analysis, University of Missouri,

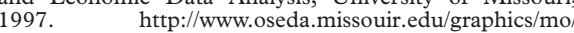
UPOV89.GIF

15 Rothman KJ, Greenland S. Modern epidemiology. 2nd Ed. Philadelphia: Lippincott-Raven, 1998.

16 Banco L, Lapidus G, Zavoski R, et al. Burn injuries among children in an urban emergency department. Pediatr Emerg Care 1994;10:98-101.
17 Zeitlin R, Somppi E, Jarnberg J. Paediatric burns in Central Finland between the 1960s and the 1980s. Burns 1993;19: 418-22.

18 Herd AN, Widdowson P, Tanner NSB. Scalds in the very young: prevention or cure? Burns 1986;12:246-9.

19 Waller AE, Marshall SW. Childhood thermal injuries in New Zealand resulting in death and hospitalization. Burns 1993;19:371-6.

20 Ryan CA, Shankowsky HA, Tredget EE. Profile of the paediatric burn patient in a Canadian burn centre. Burns 1992;18:267-72.

21 Green AR, Fairclough J, Sykes PJ. Epidemiology of burns in childhood. Burns 1984;10:368-71.

22 Bradshaw C, Hawkins J, Leach M, et al. A study of childhood scalds. Burns 1988;14:21-4.

23 Dedovic Z, Brychta P, Koupilova I, et al. Epidemiology of childhood burns at the Burn Centre in Brno, Czech Republic. Burns 1996;22:125-9.

24 Klasen HJ, ten Duis HJ. Changing patterns in the causes of scalds in young Dutch children. Burns 1986;12:563-6.

25 Lyngdorf P. Epidemiology of scalds in small children. Burns 1986;12:250-3.

26 Phillips W, Mahairas E, Hunt D, et al. The epidemiology of childhood scalds in Brisbane. Burns 1986;12:343-50.

27 Chapman JC, Sarhadi NS, Watson ACH. Declining incidence of paediatric burns in Scotland: a review of 1114 children with burns treated as inpatients and outpatients in a regional centre. Burns 1994;20:106-10.

28 Lindblad BE, Terkelsen CJ. Domestic burns among children. Burns 1990;16:254-6.

29 Brigham PA, McLoughlin E. Burn incidence and medical care use in the United States: estimates, trends, and data sources. F Burn Care Rehabil 1996;17:95-107.

30 Smith GA, Knapp JF, Barnett TM, et al. The rockets' red glare, the bombs bursting in air: fireworks-related injuries to children. Pediatrics 1996;98:1-9.

31 Rivara FP, Calonge N, Thompson RS. Population-based study of unintentional injury incidence and impact during childhood. Am f Public Health 1989;79:990-4.

32 Rivara FP, Grossman DC. Prevention of traumatic deaths to children in the United States: how far have we come and where do we need to go? Pediatrics 1996;97:791-7.

33 Cooper A, Barlow B, Davidson L, et al. Epidemiology of pediatric trauma: importance of population-based statistics. F Pediatric Surg 1992;27:149-54.

34 Klauber MR, Barrett-Connor E, Hofstetter CR, et al. A population-based study of nonfatal childhood injuries. Prev Med 1986;15:139-49.

35 Harel Y, Overpeck MD, Jones DH, et al. The effects of recall on estimating annual nonfatal injury rates for children and adolescents. Am f Public Health 1994;84:599-605.

36 Sniezek JE, Finklea JF, Graitcer PL. Injury coding and hospital discharge data. $\mathscr{f} A M A$ 1989;262:2270-2.

37 Guyer B, Berenholz G, Gallagher SS. Injury surveillance using hospital discharge abstracts coded by external cause of injury (E code). F Trauma 1990;30:470-3.

38 Marganitt B, MacKenzie EJ, Deshpande JK, et al. Hospitalizations for traumatic injures among children in Maryland: trends for incidence and severity: 1979 through 1988. Pediatrics 1992;89:608-13.

39 Ribbeck BM, Runge JW, Thomason MH, et al. Injury surveillance: a method for recording E-codes for injured emergency department patients. Ann Emerg Med 1992;21: 37-40.

40 Garrison HG, Runyan CW, Tintinalli JE, et al. Emergency department surveillance: an examination of issues and a proposal for a national strategy. Ann Emerg Med 1994;24: 849-56.

41 American Academy of Pediatrics, Committee on Injury and Poison Prevention. The hospital record of the injured child and the need for external cause-of-injury codes. Pediatrics 1999;103:524-6.

42 Schwartz RJ, Nightingale BS, Boisoneau D, et al. Accuracy of E-codes assigned to emergency department records. Acad Emerg Med 1995;2:615-20.

43 Langlios JA, Buechner JS, O'Connor EA, et al. Improving the E-coding of hospitalizations for injury: do hospital records contain adequate documentation? Am 7 Public Health 1995;85:1261-5.

44 Anonymous. Recommended framework for presenting injury mortality data. MMWR Morb Mortal Wkly Rep 1997;46(RR-14):1-30 